\title{
Bladder preservation in non-metastatic muscle-invasive bladder cancer (MIBC): a single-institution experience
}

\author{
Marianna A. Gerardi'1,2, Barbara A. Jereczek-Fossa1,2, Dario Zerini' ${ }^{2}$, Alessia Surgo',2, Samantha Dicuonzo ${ }^{1,2}$, Ruggero Spoto ${ }^{1,2}$, \\ Cristiana Fodor ${ }^{2}$, Elena Verri ${ }^{3}$, Maria Cossu Rocca ${ }^{3}$, Franco Nolè ${ }^{3}$, Matteo Muto ${ }^{1,2}$, Matteo Ferro ${ }^{4}$, Gennaro Musi ${ }^{4}$, Danilo Bottero ${ }^{4}$, \\ Deliu V. Matei ${ }^{4}$, Ottavio De Cobelli ${ }^{1,4}$ and Roberto Orecchia ${ }^{1,2}$
}

\begin{abstract}
1Department of Oncology and Haemato-oncology, University of Milan, 20122 Milan, Italy 2Division of Radiotherapy, European Institute of Oncology IRCCS, 20141 Milan, Italy

${ }^{3}$ Medical Division of Urogenital Tumours, European Institute of Oncology IRCCS, 20141 Milan, Italy

${ }^{4}$ Division of Urologic Cancer Surgery, European Institute of Oncology IRCCS, 20141 Milan, Italy
\end{abstract}

Correspondence to: Marianna Alessandra Gerardi. Email: marianna.gerardi@ieo.it

\begin{abstract}
The aim of this study is to access the feasibility, toxicity profile, and tumour outcome of an organ preservation curative approach in non-metastatic muscle-invasive bladder cancer.

A retrospective analysis was conducted on patients affected by MO bladder cancer, who refused cystectomy and were treated with a curative approach. The standard bladder preservation scheme included maximal transurethral resection of bladder tumour (TURBT) and combination of radiotherapy and platin-based chemotherapy, followed by endoscopic evaluation, urine cytology, and instrumental evaluation.
\end{abstract}

Thirteen patients fulfilled the inclusion criteria. TNM stage was cT2cNOMO and CT2cNxM0, in 12 and one patients, respectively. All patients had transitional cell cancer. Twelve patients completed the whole therapeutic programme (a bimodal treatment without chemotherapy for one patient). Median follow-up is 36 months. None of the patients developed severe urinary or intestinal acute toxicity. In 10 patients with a follow-up > 6 months, no cases of severe late toxicity were observed. Response evaluated in 12 patients included complete response and stable disease in 11 patients (92\%), and one patient (8\%), respectively. At the time of data analysis (March 2016), 10 patients (77\%) are alive with no evidence of disease, two patients (15\%) died for other reasons, and one patient has suspicious persistent local disease.

The trimodality approach, including maximal TURBT, radiotherapy, and chemotherapy for muscle-invasive bladder cancer, is well-tolerated and might be considered a valid and feasible option in fit patients who refuse radical cystectomy.

Keywords: concomitant chemoradiotherapy, organ preservation, trimodality, urinary bladder cancer

Published: $14 / 07 / 2016$

Received: 24/04/2016

ecancer 2016, 10:657 DOI: 10.3332/ecancer.2016.657

Copyright: $\odot$ the authors; licensee ecancermedicalscience. This is an Open Access article distributed under the terms of the Creative Commons Attribution License (http://creativecommons.org/licenses/by/3.0), which permits unrestricted use, distribution, and reproduction in any medium, provided the original work is properly cited. 


\section{Introduction}

The standard treatment for muscle-invasive bladder cancer remains radical cystectomy, with removal of bladder, regional lymph nodes (extended lymph node dissection) and surrounding structures (uterus or prostate gland), with urinary diversion [1-2]. This procedure is still associated with complication rates of up to $30 \%$ and, moreover, urinary diversion has a great impact on long-term urinary, gastrointestinal, and sexual function, decreasing significantly the patient's quality of life [3-4].

Two cohorts of patients could benefit from a conservative approach: patients with a limited disease who wish to avoid aggressive surgery and patients with severe comorbidities who are not candidates for radical cystectomy.

Single modality bladder-preservation treatment consisting of transurethral resection of bladder tumour (TURBT), chemotherapy, or radiotherapy yields inferior results in terms of local tumour control and long-term survival [5-6].

No randomised studies comparing radical cystectomy and the bladder-sparing approach have been completed: the SPARE (Selective bladder Preservation Against Radical Excision) trial which expected to randomly compare radical cystectomy versus bladder preservation has been closed due to poor accrual [7]. Several prospective studies has been conducted over the past two decades showing survival rates of a trimodality approach, comparable to those of radical cystectomy or neoadjuvant chemotherapy followed by cystectomy series [8-11]. This combined treatment is based on maximal TURBT, followed by radiotherapy and concurrent chemotherapy.

Long-term data, recently published by the Radiation Therapy Oncology Group (RTOG), are important in establishing selective bladderpreserving treatments as a safe and effective alternative to cystectomy [12].

Consequently, bladder preservation is now considered as an option by the guidelines of the major scientific societies (National Comprehensive Cancer Network, European Association of Urology EAU) for selected patients [13-14]. However, our recent survey showed that bladder preservation is rarely used in Lombardy (Milan area), despite the availability of the latest radiotherapy technologies and the presence of a urology tumour board in at least half of the centres [15]. Our purpose, at the European Institute of Oncology, Milan, was to retrospectively analyse the feasibility, toxicity profile, and tumour control of the trimodality approach in non-metastatic muscle-invasive bladder cancer.

\section{Material and methods}

The inclusion criteria in this retrospective study were as follows: (1) non-metastatic bladder cancer patients who refused cystectomy or were unfit for surgery; (2) patients treated with a trimodality approach, based on a combination of maximal TURBT, radiotherapy, and chemotherapy, with a curative intent; (3) written consensus for the treatment; (4) consent for the use of the data for educational and research purposes.

We retrospectively reviewed the medical records, treatments charts, radiotherapy plans, and follow-up appointments. In cases of missing follow-up data, the patients or their family doctors were contacted.

A radiological total-body evaluation was performed at the time of diagnosis to exclude other sites of disease. The approach was discussed, in all cases, by the institutional multidisciplinary tumour board. After the first TURBT showing muscle-invasive bladder cancer $(>\mathrm{T} 2)$, the trimodality regimen was undertaken including the second maximal TURBT followed by radiation therapy + concomitant chemotherapy and evaluation (urine cytology, endoscopic evaluation, and radiological examination).

At the conclusion of the whole treatment, all patients were radiologically evaluated and, in cases of no evidence of disease, follow-up was undertaken.

Evaluation of acute and late toxicity was performed according to Common Terminology Criteria for Adverse Events (CTCAE v4.0) and the Radiation Therapy Oncology Group/European Organisation for Research and Treatment of Cancer (RTOG/EORTC) scoring systems [16-17]. 


\section{Results}

Thirteen patients met the criteria of our study (five females and eight males, median age 65 years at the time of diagnosis) (Table 1). All patients were treated in our Institute, between June 2006 and January 2016.

The initial stage, according to the TNM stage system, was defined as cT2 cN0 for 12 patients, cT2 cNx for one patient with two suspicious pelvic enlarged nodes (about $1 \mathrm{~cm}$ diameter) on the staging abdominal CT with contrast. Non-metastatic disease was confirmed in all patients. Histology included transitional cell cancer in all cases.

Table 1. Patient, tumour, and maximum toxicity evaluated during chemoradiotherapy.

\begin{tabular}{|c|c|c|}
\hline Patients & $N$ patients (tot 13 ) & Percentage \\
\hline \multicolumn{3}{|l|}{ Patient characteristics } \\
\hline $\begin{array}{l}\text { Age (years) } \\
\text { Mean } \\
\text { Range } \\
\text { Gender } \\
\text { Male } \\
\text { Female } \\
\text { Smoker } \\
\text { Yes } \\
\text { No } \\
\text { Unknown }\end{array}$ & $\begin{array}{c}65 \\
42-80 \\
\\
8 \\
5 \\
\\
8 \text { (4 ex-smoker) } \\
2 \\
3 \\
\end{array}$ & $\begin{array}{c}61.5 \% \\
38.5 \% \\
61.5 \% \\
15.4 \% \\
23 \% \\
\end{array}$ \\
\hline \multicolumn{3}{|l|}{ Tumour characteristics } \\
\hline $\begin{array}{l}\text { Histology } \\
\text { Transitional cell cancer } \\
\text { Primary tumour stage } \\
\text { T2 } \\
\text { T3 } \\
\text { T4 } \\
\text { Regional lymph node stage } \\
\text { N0 } \\
\text { Nx } \\
\text { Hydronephrosis } \\
\text { Yes } \\
\text { No }\end{array}$ & $\begin{array}{c}12 \\
1 \\
\\
\\
1 \\
12 \\
\end{array}$ & $\begin{array}{c}100 \% \\
100 \% \\
- \\
- \\
\\
92 \% \\
8 \% \\
\\
\\
8 \% \\
92 \%\end{array}$ \\
\hline $\begin{array}{l}\text { Toxicity } \\
\text { RTOG/EORTC scale (15) }\end{array}$ & & \\
\hline $\begin{array}{l}\text { Genitourinary } \\
\text { Grade } 0 \\
\text { Grade } 1 \\
\text { Grade } 2 \\
\text { Grade } 3 \\
\text { Gastrointestinal } \\
\text { Grade } 0 \\
\text { Grade } 1\end{array}$ & $\begin{array}{l}2 \\
7 \\
4 \\
-\end{array}$ & $\begin{array}{c}15 \% \\
54 \% \\
31 \% \\
-\end{array}$ \\
\hline
\end{tabular}


Table 1. (Continued.)

\begin{tabular}{|c|c|c|}
\hline \multicolumn{3}{|l|}{$\begin{array}{l}\text { Toxicity } \\
\text { CTCAE v4.0 (14) }\end{array}$} \\
\hline Urinary & & \\
\hline Grade 0 & 2 & $15.4 \%$ \\
\hline Grade 1 & 6 & $46.1 \%$ \\
\hline Grade 2 & 5 & $38.5 \%$ \\
\hline Gastrointestinal & & \\
\hline Grade 0 & 7 & $54 \%$ \\
\hline Grade 1 & 6 & $46 \%$ \\
\hline Anaemia & & \\
\hline Grade 0 & 10 & $77 \%$ \\
\hline Grade 1 & 2 & $15.4 \%$ \\
\hline Grade 3 & 1 & $7.6 \%$ \\
\hline Asthenia & & \\
\hline Grade 0 & 7 & $53.6 \%$ \\
\hline Grade 1 & 4 & $31 \%$ \\
\hline Grade 2 & 2 & $15.4 \%$ \\
\hline Leucopenia & & \\
\hline Grade 0 & 10 & $77 \%$ \\
\hline Grade 1 & 2 & $15.4 \%$ \\
\hline Grade 2 & 1 & $7.6 \%$ \\
\hline Thrombocytopenia & & \\
\hline Grade 0 & 12 & $92 \%$ \\
\hline Grade 1 & 1 & $8 \%$ \\
\hline Nausea & & \\
\hline Grade 0 & 8 & $61.5 \%$ \\
\hline Grade 1 & 5 & $38.5 \%$ \\
\hline Pelvic pain & & \\
\hline Grade 0 & 11 & $84.6 \%$ \\
\hline Grade 2 & 2 & $15.4 \%$ \\
\hline Alopecia & & \\
\hline Grade 0 & 12 & $92 \%$ \\
\hline Grade & 1 & $8 \%$ \\
\hline
\end{tabular}

In 10 patients, bladder preservation was administered for patients' choice. In the other three patients, the conservative programme was chosen for clinical reasons.

Eleven patients completed the trimodality programme, including maximal TURBT followed by external radiation therapy and concomitant chemotherapy. One patient, affected by an important psychiatric disease, did not finish the whole programme, and we considered the treatment ended at the $24^{\text {th }}$ fraction of radiotherapy.

In one patient with cardiac disorders (arrhythmia requiring pace-maker) no chemotherapy was administered during radiotherapy.

The external radiotherapy included the whole pelvis. In the initial study period, two patients were treated with three-dimensional (3D) conformal external beam radiotherapy through a four-field box technique. The following 11 patients underwent image-guided intensitymodulated radiotherapy (IG-IMRT), all with daily fractions in five consecutive days each week (Figure 1).

The treatment volumes included the bladder (with a median dose of $56 \mathrm{~Gy}$ ), pelvic lymph nodes (with a median dose of $49 \mathrm{~Gy}$ ) and a boost on the site of previous tumour (with a median dose of $62 \mathrm{~Gy}$ ), determined by computed tomography (CT) scan, clinical information (pre-TURBT data, TURBT report, etc.) and magnetic resonance imaging (MRI), if available. IG-IMRT was performed on the outpatient basis. 
As radiosensitising chemotherapy was employed weekly cisplatin $\left(20 \mathrm{mg} / \mathrm{m}^{2} / \mathrm{d}\right.$, one day per week) or carboplatin (area under curve, one day per week) in nine and three patients, respectively. Carboplatin was used in patients with renal insufficiency or with another comorbidity contraindicating cisplatin use.

Six patients received adjuvant chemotherapy with cisplatin and gemcitabine for two or three courses, following the therapeutic scheme showed in Figure 2.

Considering the recent review published by Ploussard et al., illustrating not univocal data about the benefit of adjuvant chemotherapy [18], and according to EAU Guidelines [14], the following six patients received only chemotherapy concomitant to radiotherapy.

Two months after the completion of chemoradiotherapy, endoscopic evaluation (cystoscopy or TURBT), and urine cytology were performed.

During concomitant chemoradiotherapy, none of the patients developed acute G3-G4 urinary or gastroenteric toxicity. We observed neither an increase in grade 3-4 haematological toxicity and neuropathy with concurrent chemotherapy nor a decrease in treatment completion rates caused by cumulative toxicity.

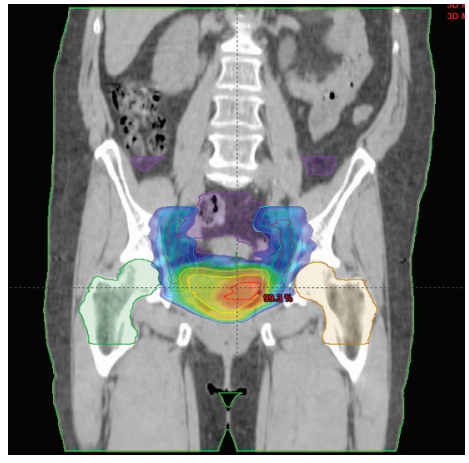

Figure 1. Dose distribution and volumes of IG-IMRT plan with the concomitant irradiation of lymph nodes of the small pelvis, whole bladder and a simultaneous concomitant boost to the site of the bladder tumour.

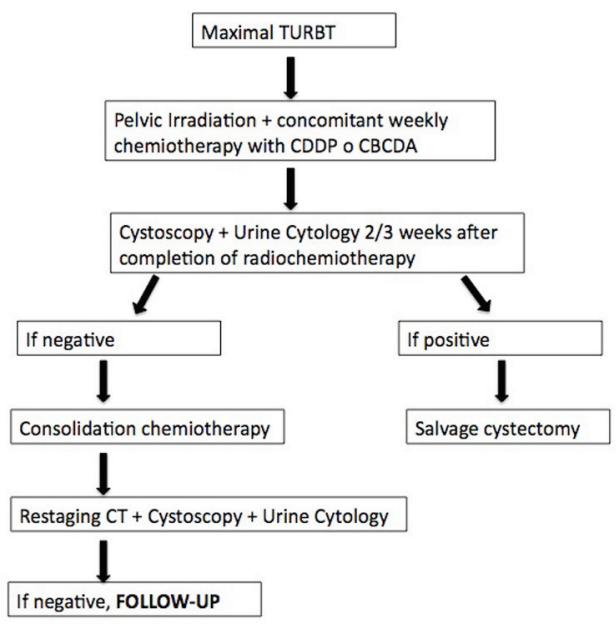

Figure 2. Schematic representation of the decision-making process in patients treated with bladder-sparing approach. 
One patient, affected concomitantly by multiple myeloma, showed a G3 haematological event and interrupted adjuvant chemotherapy after one course to receive support therapy. During adjuvant chemotherapy, one patient experienced a pulmonary embolism and one patient renal failure treated with adequate symptomatic therapy.

In 10 patients with a follow-up longer than 6 months, no cases of G3-G4 genitourinary and gastrointestinal toxicity were reported. The median follow-up is 36 months (range $2-101$ months).

Twelve patients were evaluable for clinical response. Complete tumour response at the first follow-up, considered as the negativity of endoscopic examination and urinary cytology, was observed in 11 patients (92\%); persistent bladder disease in one patient (8\%), evidenced at the first endoscopic evaluation. Progressive disease was observed in none of the patients. One patient developed, after 7 months, an in situ bladder recurrence and was treated with BCG (bacillus Calmette-Guérin) instillations. One patient experienced a local invasive bladder relapse, 9 months after the end of the trimodality treatment, and, consequently, underwent successful salvage cystectomy.

At the time of data analysis (March 2016), the status can be defined in all patients. Out of 13 patients, 10 patients (77\%) are alive without evidence of disease, nine of them (69\%) retain an intact bladder; one patient, with a suspect of persistent bladder tumour, is waiting for diagnostic TURBT; two patients (15\%) died, one for cardiovascular event (the same patient who interrupted chemoradiotherapy for psychiatric disease), and one for multiple myeloma.

Both of these two death cases are part of the three patients in which the conservative treatment was chosen for important comorbidities. The results observed in this patient subgroup were determined by underlying disease, even if the patient, who underwent bimodal treatment without chemotherapy, is still alive without evidence of disease after 7 months of follow-up.

The patient with $\mathrm{cNx}$ stage at diagnosis is, at the time of data analysis, alive retaining an intact bladder and without evidence of disease after a follow-up of more than 8 years.

\section{Discussion}

Our single-institutional study showed that bladder preservation approach can allow the maintenance of a well-functioning organ in a high percentage of selected patients with MIBC. Indeed, $69 \%$ of all our patients are alive with no evidence of cancer and with intact wellfunctioning urinary bladder at median follow-up of 37 months. These figures are similar to those observed in large surgical series and other bladder preservation reports [8-9].

We are aware of numerous drawbacks of our series including, apart from the fact it was a unicenter study, low number of patients, long accrual time, and retrospective character. However, to the best of our knowledge, this is one of the first reports on bladder preservation from Lombardy showing feasibility and good results, in particular, in fit patients (8 out of 10 fit patients, i.e., $80 \%$, remain alive with intact bladder). We do believe our experience will encourage other multidisciplinary teams to consider bladder preservation in selected fit patients [15].

The long accrual time observed in our study reflects the common issue of the treatment choice in muscle-invasive bladder cancer. This is probably due to the poor spread of conservative treatments for invasive bladder cancer in our clinical practice despite numerous recent reviews showing encouraging results of trimodality therapy in selected patients [19-22].

In the absence of randomised trials, it is difficult to compare bladder preservation with standard cystectomy, because of the wide heterogeneity in patient selection. Interestingly, a recent systematic review of clinical retrospective and prospective trials including 13,396 patients, showed the median five-year overall survival rate of $57 \%$ in the trimodality group, when compared with $52 \%(p=0.04), 51 \%$ $(p=0.02)$, and $53 \%(p=0.38)$ in the whole group receiving radical cystectomy or the group treated with radical cystectomy alone or radical cystectomy+chemotherapy, respectively [10]. Indeed, some investigators ask the provocative question on the organ-sparing multimodality treatment for muscle-invasive bladder cancer: can we continue to ignore the evidence? [23].

The ideal candidate for bladder preservation are fit patients with a small tumour (less than $5 \mathrm{~cm}$ ), unifocal, no microscopic residual after TURBT, the absence of ureteral obstruction or hydronephrosis, no association with in situ carcinoma (accurately diagnosed by biopsies of suspicious areas and analysis of histology of previous TURBT) no evidence of pelvic lymph node disease [24-25]. A recent review 
published by Smith et al. shows that $10-15 \%$ of medically operable patients are good candidates for bladder preservation [21]. In our series, all patients met the criteria for the conservative treatment as alternative to radical cystectomy.

The toxicity of trimodality approach, employed in our study, was acceptable with no direct radiotherapy-related severe events. Except in studies using neoadjuvant or adjuvant chemotherapy, where toxicity seems higher, this rate ranged from $10 \%$ to $36 \%$, while the majority $(80-90 \%)$ of patients did complete the entire course of treatment. The main toxicities are haematological, gastrointestinal, and genitourinary. Neuropathy may be reported in cases of cisplatin-based concurrent chemotherapy. The BC2001 trial reported neither an increase in G3-G4 toxicity with concurrent chemotherapy compared with radiotherapy alone nor a decrease in radiotherapy completion rates caused by toxicity [25].

In the earlier literature series, cystectomy for contracted bladder was necessary in up to $2 \%$ of patients receiving a conservative approach [21]. In our patients, the complications have been observed predominantly during adjuvant chemotherapy (G3 myelotoxicity, renal failure, and lung thromboembolism), confirming higher toxicity of concomitant and adjuvant chemotherapy in respect of concomitant only chemotherapy in bladder cancer preservation; this finding confirms the fragile general conditions of the bladder cancer patients. Indeed, the most recent bladder preservation reports claim that TURBT followed by concomitant chemoradiotherapy (with no adjuvant or neoadjuvant chemotherapy) may be considered the optimal approach in terms of tolerability and efficacy [26].

From our limited experience, we learnt two essential assumptions: first, patients' good compliance is fundamental during the active treatment and subsequently, because of the need both of prompt salvage cystectomy in cases of no tumour response or local failure, and of lifelong surveillance; second, in such an assessment, a close and continuous collaboration between Urologists, Medical Oncologists and Radiation Oncologists becomes of extreme importance, in order to reach an optimal multidisciplinary approach. In Lombardy, a prospective observational study on the bladder preservation has been just undertaken reinforcing uro-oncology teamwork.

\section{Conclusion}

In conclusion, the trimodality approach including maximal TURBT, radiotherapy, and chemotherapy for muscle-invasive bladder cancer, in patients who refuse radical cystectomy or are unfit for surgery, could be considered as a good and feasible therapeutic option and results in a low rate of acute and late toxicity.

Long-term follow-up and more prospective multicentre research are needed to confirm the results of our retrospective study.

Abbreviations used: TURBT, transurethral bladder tumour resection; G, grade; Gy, Grey, IG-IMRT, image-guided intensity-modulated radiotherapy, $\mathrm{CT}$, computed tomography; $\mathrm{RT}$, radiation therapy.

\section{References}

1. Stein JP, Lieskovsky $G$ and Cote $R$ et al (2001) Radical cystectomy in the treatment of invasive bladder cancer: long-term results in 1,054 patients $\mathrm{J}$ Clin Oncol 19 666-75 PMID: 11157016

2. Gschwend JE, Fair WR and Vieweg J (2000) Radical cystectomy for invasive bladder cancer: contemporary results and remaining controversies Eur Urol 38 121-30 DOI: 10.1159/000020268 PMID: 10895001

3. Konety BR, Allareddy $\mathrm{V}$ and Herr $\mathrm{H}$ (2006) Complications after radical cystectomy: analysis of population-based data Urology 68 58-64 DOI: 10.1016/j.urology.2006.01.051 PMID: 16806414

4. Manoharan M, Ayyathurai R and Soloway MS (2009) Radical cystectomy for urothelial carcinoma of the bladder: an analysis of perioperative and survival outcome BJU Int 104 1227-32 DOI: 10.1111/j.1464-410X.2009.08625.x PMID: 19519764

5. Shipley WU and Rose MA (1985) Bladder cancer The selection of patients for treatment by full-dose irradiation Cancer $\mathbf{5 5}$ 2278-84 PMID: $\underline{3919933}$ 
6. Sauer R, Birkenhake S and Kühn R et al (1998) Efficacy of chemoradiotherapy with platin derivatives compared to radiotherapy alone in organ-sparing treatment of bladder cancer Int J Radiat Oncol Biol Phys 40 121-7 DOI: 10.1016/S0360-3016(97)00579-8 PMID: $\underline{9422567}$

7. Huddart RA, Hall E and Lewis R et al (2010) SPARE trial management group Life and death of SPARE (Selective bladder Preservation Against Radical Excision): reflections on why the SPARE trial closed BJU Int 106 753-5 DOI: 10.1111/j.1464410X.2010.09537.x PMID: $\underline{20707796}$

8. Shipley WU, Zietman AL and Kaufman DS et al (2005) Selective bladder preservation by trimodality therapy for patients with muscularis propria invasive bladder cancer and who are cystectomy candidates-the Massachusetts general hospital and radiation therapy oncology group experiences Semin Radiat Oncol 15 36-41 DOI: 10.1016/j.semradonc.2004.07.008 PMID: 15662605

9. Martini T, Mayr R and Wehrberger $\mathrm{C}$ et al (2013) Comparison of radical cystectomy with conservative treatment in geriatric ( $\geq 80$ ) patients with muscle invasive bladder cancer Int Braz J Urol 39 622-30 DOI: 10.1590/S1677-5538.IBJU.2013.05.03 PMID: 24267105

10. Arcangeli G, Strigari $L$ and Arcangeli S (2015) Radical cystectomy versus organ-sparing trimodality treatment in muscle-invasive bladder cancer: a systematic review of clinical trials Crit Rev Oncol Hematol 95(3) 387-9 DOI: 10.1016/j.critrevonc.2015.04.006 PMID: 25934521

11. Arcangeli G, Arcangeli $S$ and Strigari $L$ (2015) A systematic review and meta-analysis of clinical trials of bladder-sparing trimodality treatment for muscle-invasive bladder cancer (MIBC) Crit Rev Oncol Hematol 94(1) 105-15 DOI: 10.1016/j.critrevonc.2014.11.007

12. Mak RH, Hunt $D$ and Shipley WU et al (2014) Long-term outcomes in patients with muscle-invasive bladder cancer after selective bladder-preserving combined-modality therapy: a pooled analysis of radiation therapy oncology group protocols 8802 , 8903, 9506, 9706, 9906, and $0233 \mathrm{~J}$ Clin Oncol 32 3801-9 DOI: 10.1200/JCO.2014.57.5548 PMID: 25366678 PMCID: 4239302

13. NCCN Clinical Practice Guidelines in Oncology, Available at: www.nccn.org/professionals/physicians_gls/f_guidelines.asp Accessed 27 June 2014

14. Witjes JA, Comperat E and Cowan NC et al (2014) European association of urology: EAU guidelines on muscle-invasive and metastatic bladder cancer: summary of the 2013 guidelines Eur Urol 65 778-92 DOI: 10.1016/j.eururo.2013.11.046 PMID: $\underline{24373477}$

15. Jereczek-Fossa BA, Colombo R and Magnani T et al (2015) Urinary bladder preservation for muscle invasive bladder cancer: a survey among radiation oncologists of Lombardy, Italy Tumori 101 174-8 DOI: 10.5301/tt.5000235 PMID: 25744865

16. Common terminology criteria for adverse events and common toxicity criteria National cancer institute cancer therapy evaluation program Available at: http://ctep.cancer.gov/protocolDevelopment/electronic applications/ctc.htm Accessed 10 October 2012.

17. Cox JD, Stetz J and Pajak TF (1995) Toxicity criteria of the radiation oncology group (RTOG) and the European organization for research and treatment of cancer (EORTC) Int J Radiat Oncol Biol Phys 31 1341-6 DOI: 10.1016/0360-3016(95)00060-C PMID: $\underline{7713792}$

18. Ploussard G, Daneshmand S and Efstathiou JA et al (2014) Critical analysis of bladder sparing with trimodal therapy in muscleinvasive bladder cancer: a systematic review Eur Urol 66(1) 120-37 DOI: 10.1016/j.eururo.2014.02.038 PMID: 24613684

19. Koga $F$ and Kihara $K$ (2012) Selective bladder preservation with curative intent for muscle-invasive bladder cancer: a contemporary review Int J Urol 19 388-401 DOI: 10.1111/j.1442-2042.2012.02974.x PMID: 22409269

20. Sandler HM and Mirhadi AJ (2012) Current role of radiation therapy bladder cancer Semin Oncol 39 583-7 
21. Smith ZL, Christodouleas JP and Keefe SM et al (2013) Bladder preservation in the treatment of muscle-invasive bladder cancer (MIBC): a review of the literature and a practical approach to therapy BJU Int 112 13-25 DOI: 10.1111/j.1464-410X.2012.11762.X PMID: 23356411

22. Smith $A B$, Deal $A M$ and Woods ME et al (2014) Muscle-invasive bladder cancer: evaluating treatment and survival in the national cancer data base BJU Int 114(5) 719-26 DOI: 10.1111/bju.12601

23. Rödel C and Weiss C (2014) Organ-sparing multimodality treatment for muscle-invasive bladder cancer: can we continue to ignore the evidence? J Clin Oncol 32 3787-8 DOI: 10.1200/JCO.2014.58.5521 PMID: 25366679

24. Smith $A B$, Deal $A M$ and Woods ME et al (2014) Muscle-invasive bladder cancer: evaluating treatment and survival in the national cancer data base BJU Int 114 719-26 DOI: 10.1111/bju.12601

25. James ND, Hussain SA and Hall E et al (2012) Radiotherapy with or without chemotherapy in muscle-invasive bladder cancer N Engl J Med 366 1477-88 DOI: 10.1056/NEJMoa1106106 PMID: 22512481

26. Lee CY, Yang KL and Ko HL et al (2014) Trimodality bladder-sparing approach without neoadjuvant chemotherapy for nodenegative localized muscle-invasive urinary bladder cancer resulted in comparable cystectomy-free survival Radiat Oncol 9213 DOI: 10.1186/1748-717X-9-213 PMID: 25248470 PMCID: $\underline{4261984}$ 